\title{
Factors affecting survival of hospitalised patients with COPD
}

\author{
H. Gunen*, S.S. Hacievliyagil*, F. Kosar", L.C. Mutlu*, G. Gulbas*, E. Pehlivan", \\ I. Sahin ${ }^{+}$and O. Kizkin*
}

ABSTRACT: Factors determining in-hospital mortality and long-term survival of patients hospitalised with acute exacerbations of chronic obstructive pulmonary disease (AECOPD) are not precisely understood. The aim of the present study was to assess the parameters related to in-hospital mortality and long-term survival after hospitalisation of patients with AECOPD.

Clinical and epidemiological parameters on admission in 205 consecutive patients hospitalised with AECOPD were prospectively assessed. Patients were followed-up for 3 yrs. Factors determining short- and long-term mortality were analysed.

In total, 17 patients (8.3\%) died in hospital. In-hospital mortality was significantly associated with lower arterial oxygen tension $\left(\mathrm{Pa}_{\mathrm{a}} \mathrm{O}_{2}\right)$, higher carbon dioxide arterial tension, lower arterial oxygen saturation and longer hospital stay. The overall 6-month mortality rate was $24 \%$, with 1-, 2and $3-y r$ mortality rates of $33 \%, 39 \%$ and $49 \%$, respectively. Cox regression analysis revealed that long-term mortality was associated with longer disease duration (relative risk $(\mathbf{R R})=1.158)$, lower albumin ( $R R=0.411)$, lower $P_{a} O_{2}(R R=0.871)$ and lower body mass index $(R R=0.830)$. When the model was run for the time elapsed since first hospitalisation, it also appeared as statistically significant $(R R=1.195)$.

These findings show that patients hospitalised with acute exacerbations of chronic obstructive pulmonary disease have poor short- and long-term survival. Prediction of survival status may be enhanced by considering arterial oxygen tension, albumin, body mass index, disease duration and time elapsed since the first hospitalisation.

KEYWORDS: Chronic obstructive pulmonary disease, in-hospital, long-term survival, mortality

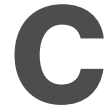
hronic obstructive pulmonary disease (COPD) is a leading cause of death and disability worldwide. According to World Bank data, it is expected to move from its status in 2000 as the 4th and 12th most frequent cause of mortality and morbidity, respectively, to be the $3 \mathrm{rd}$ and 5 th leading cause of mortality and morbidity, respectively, in 2020 $[1,2]$. Moreover, about $10 \%$ of all hospitalisations are directly or indirectly attributable to COPD [3].

Despite being the only major disease showing increasing trends, factors that determine the short- and long-term outcomes of patients with COPD are not yet precisely understood. Identification of the factors that may influence survival in patients with COPD may enable clinicians to better assess life expectancy. This is extremely important, in that it may help offset the social and economic burden of COPD through the implementation of more individualised and effective treatment strategies, as well as better mobilising healthcare resources.
Investigations into the factors predicting outcome in COPD patients have included follow-up studies on stable COPD patients and on COPD patients admitted to the intensive care unit (ICU), as well as on patients admitted to hospital with hypercapneic acute attack. Among the parameters thought to be related to mortality are forced expiratory volume in one second (FEV1) [4], carbon dioxide arterial tension $\left(\mathrm{Pa}_{\mathrm{a}}, \mathrm{CO}_{2}\right)$, arterial oxygenation [5], cardiac status [6], body mass index (BMI) [7], serum albumin level, functional status [8] and the presence of other comorbid states [9]. In a study that directly addressed the long-term outcome for COPD patients admitted to hospital, the in-hospital and 2-yr after-discharge mortality rates were found to be $11 \%$ and $49 \%$, respectively [8]. CONNORS et al. [8] even developed a multivariate model to predict the probability of survival of patients hospitalised with an acute exacerbation. There is only one prospective study that assessed the in-hospital and after-discharge outcome for all COPD patients admitted with acute
AFFILIATIONS

*Dept of Pulmonary Medicine,

\#Dept of Cardiology,

'Dept of Public Health, and

${ }^{+}$Dept of Internal Medicine, Turgut

Ozal Research Centre, Inonu

University, Malatya, Turkey.

CORRESPONDENCE

H. Gunen

Turgut Ozal Research Centre

Inonu University

Dept of Pulmonary Medicine

Malatya

44069 Turkey

Fax: 904223410728

E-mail: hgunen@yahoo.com

Received:

February 262004

Accepted after revision:

April 112005 
exacerbation [9]. Although the follow-up period was relatively short, it was found that $8 \%$ of patients died in hospital and $23 \%$ died within 1 yr after hospitalisation [9].

In the present study, the authors sought to prospectively identify factors that may influence in-hospital deaths and deaths after discharge in a large patient cohort. The current study differs from previous studies in that all COPD patients hospitalised for acute exacerbation were included, and the follow-up period was 3 yrs.

\section{METHODS}

\section{Patients and study protocol}

The study was conducted on all COPD patients with acute exacerbation admitted to the pulmonary department at Turgut Ozal Research Centre, Inonu University (Malatya, Turkey) between January 1999 and October 2000. This is a university hospital that also serves as the largest regional hospital, thus ensuring that the study population was a representative selection of pulmonary patients in the region. Diagnosis of COPD was made according to the criteria set by the American Thoracic Society (ATS) [10]. An acute attack was defined as the presence of a worsening in at least two of the following symptoms: cough, purulent sputum and dyspnoea. Patients were hospitalised for one or more of the following indications: severely increased symptoms; new onset of cyanosis and peripheral oedema; confusion; lethargy; coma; use of accessory muscles for ventilation; significant comorbidities; failure to respond to initial treatment; judgment that treatment at home is insufficient; acidosis; persistent or worsening hypoxemia and/or severe or worsening hypercapnia and new onset arrhythmias. COPD patients hospitalised for specific (secondary) causes, such as pneumonia, pulmonary emboli, congestive heart failure or lung cancer, as the cause of acute exacerbation were excluded. Each patient was enrolled in the study only once, at initial hospitalisation. Each patient was treated in a standard fashion with $40 \mathrm{mg}$ of i.v. prednisolone per day, nebulised bronchodilators (inhaled salbutamol and ipratropium bromide), theophylline and supplemental oxygen. Antibiotics were used where there were signs of bacterial infection. In addition, some patients with respiratory failure were admitted to the ICU.

\section{Data collection}

Demographic and clinical data were collected for all patients including: age; sex; socio-economic and marital status; availability of medical insurance; smoking load (pack-yrs); detailed haemogram; and biochemical, spirometric and arterial blood gas analysis at admission. In addition, admission to the ICU, length of hospital stay, BMI, systolic pulmonary artery pressure $(\mathrm{Ppa})$, age at disease onset, time elapsed since first hospitalisation and duration of disease were also noted for each patient. For the determination of disease duration, the date of first visit to a doctor for chronic complaints of cough, dyspnoea and sputum production was used. This information, and time elapsed since first hospitalisation, were obtained from reviews of personal and official medical documents and by questioning the patients. The score for time elapsed since first hospitalisation was entered as zero in cases where the index hospitalisation was the first hospitalisation. Comorbidity was measured for all patients according to the model developed by CHARLSON et al. [11]. This index gives different scores for various chronic illnesses to predict mortality. Using this method, severe diseases are assigned higher scores, and milder diseases are assigned lower scores (e.g. congestive heart failure $=1$, malignancy $=2$, severe liver disease $=3$, AIDS $=6$ ) . These data were evaluated to determine the factors that may influence in-hospital deaths and those that may influence overall survival time. Patients' survival status was assessed by reviewing patient charts and state records, and by telephone calls. Each patient was assessed at intervals of 3-6 months for 3 yrs. In the event of death, the date of death was confirmed by death certificates, official statements in their charts and relatives' statements.

\section{Measurements}

Standard spirometric examination at admission was performed using a Vmax 20c spirometer (SensorMedics Corp., Yorba-Linda, CA, USA), with the spirograms having the largest FEV1 and forced vital capacity (FVC), selected from at least two technically acceptable spirometric measurements being used in the analysis. If spirometric measurements could not be performed just after admission, they were performed as soon as possible within $24 \mathrm{~h}$. Spirograms delayed beyond this time were not processed further. For each patient, classification of disease severity was performed as described in the latest European Respiratory Society (ERS)/ATS statements for COPD using the spirograms obtained during a stable period or $\geqslant 4$ weeks after discharge [12]. During these spirometric measurements, ATS instructions were followed [13]. Immediately after admission, arterial blood gas analysis was performed on all patients while breathing room air at rest. Systolic Ppa was measured by two-dimensional and colourflow Doppler echocardiography (ATLHDI 5000 CV; Mechatronics Inc., Preston, WA, USA). The technique and reliability of the method are described elsewhere [14, 15].

\section{Treatment after discharge}

Patients were treated in a standard fashion during follow-up after discharge. All patients received regular inhaled anticholinergic agents combined with short-acting $\beta_{2}$ agonists and theophylline preparations, and 169 patients (90\%) used regular inhaled corticosteroids. Diuretics, cardiac glycosides and antiarrythmic agents were prescribed where indicated. In addition, 63 patients were placed on long-term oxygen treatment.

\section{Statistical analysis}

All data are expressed as mean $\pm \mathrm{SD}$. The distribution of nominal variables was compared using the Chi-squared test. To better assess the factors that may be related to in-hospital mortality, comparison of continuous variables between the groups was performed using the unpaired t-test. For prediction of in-hospital mortality, sensitivity and specificity were analysed using the receiver operating characteristic curve method. The relationship between mortality after hospitalisation and patient characteristics was determined using a Cox proportional hazards model. The independent parameters included age, duration of disease, smoking load (pack-yrs), length of hospital stay, FEV1, FEV1/FVC, arterial oxygen tension $\left(\mathrm{Pa}_{2} \mathrm{O}_{2}\right), \mathrm{Pa}_{\mathrm{a}} \mathrm{CO}_{2}, \mathrm{BMI}$, systolic $P$ pa, serum albumin level and comorbidity index. The model was run a second time after 


\begin{tabular}{|c|c|c|c|c|}
\hline Characteristics & All patients & Alive cases & Patients who died at the hospital & p-value \\
\hline Subjects $n$ & 205 & 188 & 17 & \\
\hline Age yrs & $64.8 \pm 9.3$ & $64.8 \pm 9.3$ & $64.9 \pm 9.4$ & NS \\
\hline Sex female/male & $25 / 180$ & $23 / 165$ & $2 / 15$ & NS \\
\hline Smoking status yes/ex/never & $95 / 83 / 27$ & $88 / 75 / 25$ & $7 / 8 / 2$ & NS \\
\hline Smoke load pack-yrs & $48.6 \pm 30.8$ & $47.4 \pm 29.4$ & $61.1 \pm 41.2$ & NS \\
\hline Duration hospital stay days & $11.6 \pm 5.5$ & $11.4 \pm 4.3$ & $14.2 \pm 12.1$ & 0.042 \\
\hline Albumin $\mathbf{g} \cdot \mathbf{d L}^{-1}$ & $3.4 \pm 0.8$ & $3.4 \pm 0.8$ & $3.5 \pm 0.5$ & NS \\
\hline $\mathrm{Pa}, \mathrm{CO}_{2} \mathrm{mmHg}$ & $48.9 \pm 12.5$ & $48.2 \pm 12.8$ & $55.6 \pm 5.6$ & 0.019 \\
\hline $\mathrm{Sa}, \mathrm{O}_{2}$ & $80.2 \pm 11.5$ & $80.9 \pm 11.1$ & $73.4 \pm 13.5$ & 0.01 \\
\hline pH & $7.41 \pm 0.07$ & $7.41 \pm 0.07$ & $7.40 \pm 0.09$ & NS \\
\hline $\mathrm{BMI} \mathbf{k g} \cdot \mathrm{m}^{-2}$ & $23.1 \pm 4.8$ & $23.2 \pm 4.9$ & $20.6 \pm 2.3$ & NS \\
\hline Ppa mmHg & $48.9 \pm 8.1$ & $49.1 \pm 8.0$ & $48.1 \pm 9.7$ & NS \\
\hline Long-term oxygen treatment & 57 & 50 & 7 & NS \\
\hline Comorbidity index & $1.59 \pm 0.8$ & $1.59 \pm 0.8$ & $1.61 \pm 0.9$ & NS \\
\hline Patients with medical insurance & 96 & 96 & 94 & NS \\
\hline Married or living with relatives & 93 & 93 & 94 & NS \\
\hline
\end{tabular}

Data presented as mean $\pm \mathrm{SD}, \mathrm{n}$ or \%, unless otherwise stated. $\mathrm{FVC}$ : forced vital capacity; $\mathrm{FEV} 1$ : forced expiratory volume in one second; $P \mathrm{~Pa}_{1} \mathrm{O}_{2}$; arterial oxygen tension; $\mathrm{Pa}_{1} \mathrm{CO}_{2}$ : carbon dioxide arterial tension; $\mathrm{Sa}, \mathrm{O}_{2}$ : arterial oxygen saturation; $\mathrm{BMI}$ : body mass index; $\mathrm{Ppa}$ : systolic pulmonary artery pressure; NS: not significant.

substituting duration of disease by time elapsed since first hospitalisation. The Pearson correlation coefficient was calculated to assess the relationship between duration of disease and time elapsed since first hospitalisation. These independent parameters were selected primarily as a result of previous studies suggesting their relationship to survival in COPD patients. Since maintenance systemic corticosteroids have not been prescribed for the long-term treatment of COPD patients in the current authors region, no patient was seen utilising them during the study period. Thus, differing from the previous studies, this parameter was not included in the regression model. In addition, to determine the influence of age at disease onset on survival, this parameter was also analysed using the authors' model. However, since this parameter is a co-factor (age-duration of disease e.g. 9-6=3), only the duration of disease and age at disease onset were entered into the Cox regression analysis. Survival of all patients was analysed using the Kaplan-Meier method. Statistically significant parameters were stratified according to clinically important thresholds, and survival analysis for each sub-group composed according to these thresholds was performed. A two-sided p-value $<0.05$ was considered to be statistically significant.

\section{RESULTS}

The mean age of the patients was $65 \mathrm{yrs}$, and $60 \%$ were aged $\geqslant 65$ yrs. Age did not seem to contribute significantly to in-hospital deaths or long-term survival. Only 25 of the 205 patients were female, in whom the main causes of exacerbation were: infections $(n=17 ; 68 \%)$, noncompliance with treatment $(\mathrm{n}=4 ; 16 \%)$ and different combinations of the primary causes including air pollution $(n=3 ; 12 \%)$. These rates were similar to those observed in male patients, in whom the main causes of exacerbation were: infections $(n=115 ; 64 \%)$, noncompliance with treatment $(\mathrm{n}=25 ; 14 \%)$ and the different combinations $(n=26 ; 14 \%)$. Due to the limited number of female patients in the study group and the standard treatment received after discharge by almost all patients, the analysis did not include detailing by sex and treatment after discharge.

Out of the 205 patients in the study group, 95 were current smokers $(46 \%), 83$ were ex-smokers $(41 \%)$ and 27 had never smoked (13\%). Smoking status and smoking load did not correlate with admission to the ICU, in-hospital mortality or long-term survival. Patients who had been receiving long-term oxygen treatment $(n=57)$ on admission did not differ from the rest of the population with regard to in-hospital mortality $(n=7)$ or admission to the ICU $(n=15 ; p>0.05$; tables 1 and 2$)$. After discharge, 63 patients received long-term oxygen treatment. Their mortality rates at 6 months, $1 \mathrm{yr}, 2$ yrs and 3 yrs were $29 \%, 37 \%, 44 \%$ and $56 \%$, respectively. No significant difference in survival was observed between this group and the rest of the study population.

Medical insurance was available to $96 \%$ of the patients, and $93 \%$ were either married or living with relatives. According to 


\begin{tabular}{|c|c|c|c|}
\hline $\begin{array}{cl}\text { TABLE } 2 & \text { Compar } \\
& \text { admittec } \\
& \text { admissic }\end{array}$ & $\begin{array}{l}\text { of the p } \\
\text { the intens } \\
\text { characteri }\end{array}$ & $\begin{array}{l}\text { its admitted } \\
\text { care unit accc }\end{array}$ & ng to the \\
\hline Characteristics & Admitted & Not admitted & p-value \\
\hline Subjects $n$ & 45 & 160 & \\
\hline Age yrs & $63.7 \pm 11.0$ & $65.2 \pm 8.6$ & NS \\
\hline Sex female/male & $2 / 15$ & $23 / 165$ & NS \\
\hline Duration of disease yrs & $11.6 \pm 9.0$ & $9.9 \pm 8.2$ & NS \\
\hline $\begin{array}{l}\text { Time elapsed since first } \\
\text { hospitalisation yrs }\end{array}$ & $5.6 \pm 6.1$ & $5.2 \pm 6.3$ & NS \\
\hline $\begin{array}{l}\text { Smoking status yes/ex/ } \\
\text { never }\end{array}$ & $18 / 22 / 5$ & $77 / 61 / 22$ & NS \\
\hline Smoke load pack-yrs & $50.4 \pm 27.7$ & $48 \pm 31.7$ & NS \\
\hline $\begin{array}{l}\text { Duration hospital stay } \\
\text { days }\end{array}$ & $11.5 \pm 6.9$ & $11.6 \pm 4.9$ & NS \\
\hline Albumin $\mathbf{g} \cdot \mathrm{dL}^{-1}$ & $3.3 \pm 0.6$ & $3.4 \pm 0.8$ & NS \\
\hline FVC \% predicted & $57.0 \pm 18.8$ & $64.5 \pm 21.6$ & 0.047 \\
\hline FEV $1 \%$ predicted & $35.3 \pm 11.3$ & $39.1 \pm 13.6$ & NS \\
\hline FEV $1 /$ FVC & $51.3 \pm 19.7$ & $49.8 \pm 15.4$ & NS \\
\hline $\mathrm{Pa}, \mathrm{O}_{2} \mathrm{mmHg}$ & $42.0 \pm 9.2$ & $49.5 \pm 13.4$ & 0.001 \\
\hline $\mathrm{Pa}, \mathrm{CO}_{2} \mathrm{mmHg}$ & $52.1 \pm 9.8$ & $47.9 \pm 13.1$ & 0.025 \\
\hline $\mathrm{Sa}, \mathrm{O}_{2}$ & $74.6 \pm 10.7$ & $82.0 \pm 11.2$ & 0.000 \\
\hline pH & $7.40 \pm 0.08$ & $7.41 \pm 0.07$ & NS \\
\hline $\mathrm{BMI} \mathbf{k g} \cdot \mathrm{m}^{-2}$ & $21.5 \pm 3.5$ & $23.5 \pm 5.0$ & NS \\
\hline Ppa mmHg & $48.1 \pm 8.0$ & $49.2 \pm 8.1$ & NS \\
\hline $\begin{array}{l}\text { Long-term oxygen } \\
\text { treatment }\end{array}$ & 15 & 42 & NS \\
\hline Comorbidity index & $1.61 \pm 0.9$ & $1.58 \pm 0.8$ & NS \\
\hline $\begin{array}{l}\text { Patients with medical } \\
\text { insurance } \%\end{array}$ & 96 & 96 & NS \\
\hline $\begin{array}{l}\text { Married or living with } \\
\text { relatives \% }\end{array}$ & 91 & 94 & NS \\
\hline
\end{tabular}

Data presented as mean $\pm \mathrm{SD}, \mathrm{n}$ or $\%$, unless otherwise stated. FVC: forced vital capacity; $\mathrm{FEV}_{1}$ : forced expiratory volume in one second; $\mathrm{Pa}, \mathrm{O}_{2}$ : arterial oxygen tension; $\mathrm{Pa}_{\mathrm{a}} \mathrm{CO}_{2}$ : carbon dioxide arterial tension; $\mathrm{Sa}, \mathrm{O}_{2}$ : arterial oxygen saturation; BMI: body mass index; Ppa: systolic pulmonary artery pressure; NS: not significant. $\mathrm{kPa}=\mathrm{mmHg} \times 0.133$.

Turkish standards, $84 \%$ of these patients belonged to the lower income group ( $<$ US $\$ 10,000$ yearly income). Due to these very high rates, analysis based on these characteristics was not performed.

The general features of the 205 patients are shown in table 1 . Although arterial blood gas analysis could be performed in all patients, spirograms could not be obtained in 22 patients; 11 due to severity of the exacerbation, five due to technical problems and six due to lack of patient cooperation. Only the omission of patients on whom a spirometric examination could not be performed due to severe exacerbation may have created a selection bias, with the potential to change the results. However, since this number is small, the probability of their having a significant impact on the results should be low. Although the best effort was made to obtain stable period spirograms for all patients, an appropriate spirometric measurement could not be obtained for 36 patients. For the rest, the ERS/ATS stage of COPD was moderate in $34 \%$ of the patients (FEV1 $50-80 \%$ predicted), severe in $44 \%$ of the patients (FEV1 $30-50 \%$ pred) and very severe in $22 \%$ of the patients (FEV $1<30 \%$ pred). None of these patients had mild COPD (FEV $1 \geqslant 80 \%$ pred).

In total, 17 patients $(8.3 \%)$ died in the hospital, whereas 188 were discharged. Comparison of these two groups revealed that longer hospital stay $(\mathrm{p}=0.042)$, lower $\mathrm{Pa}_{\mathrm{a}_{2}}(\mathrm{p}=0.019)$, lower arterial oxygen saturation $\left(\mathrm{Sa}_{2} \mathrm{O}_{2} ; \mathrm{p}=0.01\right)$ and higher $\mathrm{Pa}_{\mathrm{a}} \mathrm{CO}_{2}(\mathrm{p}=0.019)$ were significantly related to in-hospital death (table 1). The curve analysis showed that $\mathrm{Pa}_{\mathrm{a}} \mathrm{CO}_{2}$ at a cut-off of $6.916 \mathrm{kPa}$ appeared to be the only factor with a relatively high sensitivity (0.71) and specificity (0.69) for predicting in-hospital mortality. The other parameters did not give any clinically revealing values for sensitivity or specificity. Whereas the rate of in-hospital death among the 45 patients (22\%) admitted to the ICU was $27 \%$, it was $3 \%$ for the non-ICU patients (five out of 160; $\mathrm{p}=0.000)$. Clinical features of the ICU and non-ICU patients are shown in table 2 . Statistically significant differences between the ICU and non-ICU patients were FVC $(\mathrm{p}=0.047), \quad \mathrm{Pa}, \mathrm{O}_{2} \quad(\mathrm{p}=0.001), \quad \mathrm{Pa}_{1} \mathrm{CO}_{2} \quad(\mathrm{p}=0.025), \quad$ and $\mathrm{Sa}, \mathrm{O}_{2}$ $(\mathrm{p}=0.000)$.

Long-term follow-up of all hospitalised patients revealed 6 month and 1-, 2- and 3-yr overall mortality rates of $24 \%, 33 \%$, $39 \%$ and $49 \%$, respectively (fig. 1). Median survival for the patients who died during the 3-yr period was 154 days. Except for one patient, 6-month follow-up was completed for all discharged patients. In total, five, 9 and 15 patients were lost to follow-up at 1, 2 and 3 yrs, respectively. Table 3 shows the results of the Cox proportional hazard analysis. This model revealed that mortality was related to longer duration of disease (relative risk (RR) 1.158; 95\% CI 1.059-1.268; $p=0.001$ ), lower albumin level (RR 0.411; 95\% CI 0.205-0.824; $\mathrm{p}=0.012$ ), lower $\mathrm{Pa}_{\mathrm{a}} \mathrm{O}_{2}$ (RR $0.871 ; 95 \% \mathrm{CI} 0.784-0.969 ; \mathrm{p}=0.011$ ), and lower BMI (RR 0.830; 95\% CI 0.703-0.979; $\mathrm{p}=0.027$ ).

Of the 205 patients, 156 had been hospitalised previously for acute exacerbation of COPD, with the first hospitalisation occurring $\sim 5$ yrs after diagnosis of COPD. The correlation between duration of disease and time elapsed since first hospitalisation was $0.888(\mathrm{p}=0.000)$. Since both parameters conveyed essentially the same information, they were not

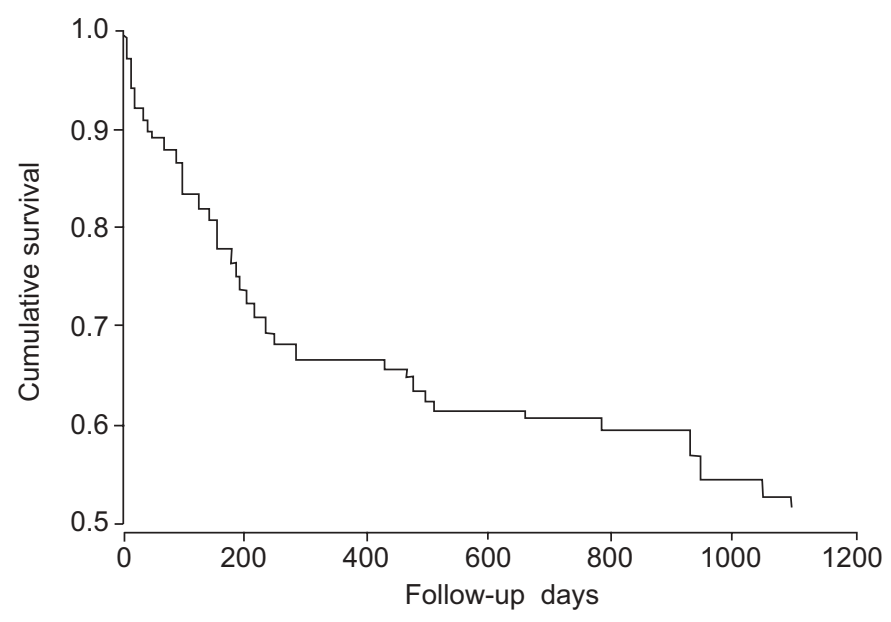

FIGURE 1. Survival curve for all patients after hospitalistion. 


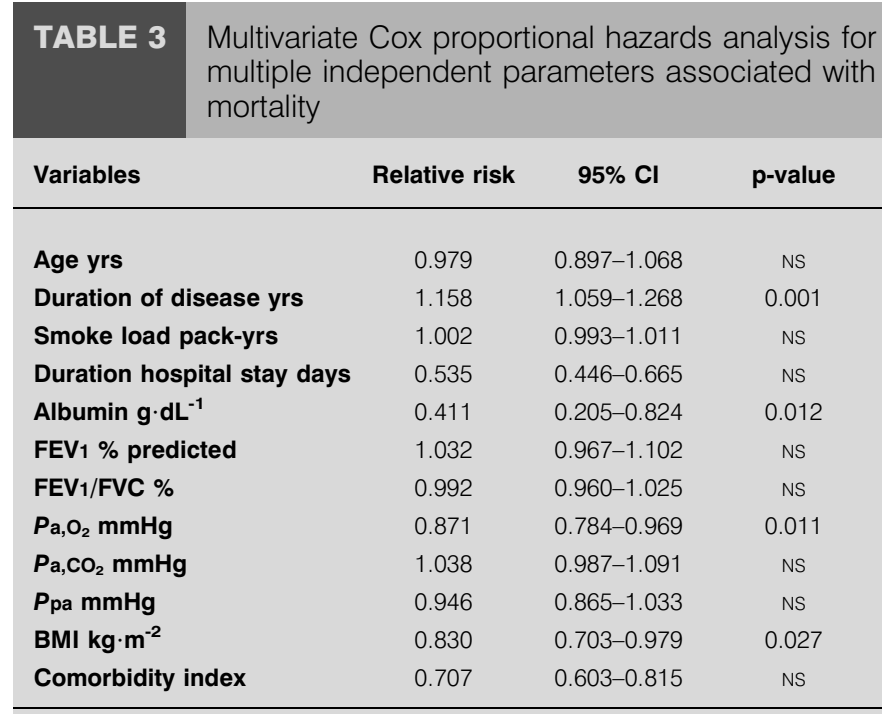

Cl: confidence interval; FEV1: forced expiratory volume in one second; FVC: forced vital capacity; $\mathrm{Pa}_{\mathrm{a}} \mathrm{O}_{2}$ : arterial oxygen tension; $\mathrm{Pa}_{1} \mathrm{CO}_{2}$ : carbon dioxide arterial tension; $P$ pa: systolic pulmonary artery pressure; $\mathrm{BMI}$ : body mass index; NS: not significant. $\mathrm{kPa}=\mathrm{mmHg} \times 0.133$

analysed simultaneously in the same model. Thus, this approach avoided the paradox of multicollinearity in the current regression model. As expected, substitution of duration of disease by time elapsed since first hospitalisation did not significantly change the statistical values of the other parameters in the model. Mortality related factors were found to be longer time since first hospitalisation (RR 1.195; 95\% CI 1.061-1.346; $\mathrm{p}=0.003)$, lower albumin level (RR 0.430; 95\% CI $0.207-0.892 ; \mathrm{p}=0.023$ ), lower $\mathrm{Pa}_{1} \mathrm{O}_{2}$ (RR $0.866 ; 95 \%$ CI 0.780 $0.962 ; \mathrm{p}=0.007$ ), and lower BMI (RR 0.795; 95\% CI 0.666-0.950; $\mathrm{p}=0.011$ ) in this second run. Longer duration of disease and longer time elapsed since first hospitalisation were observed to be new determinants of mortality. To analyse the effects of age at disease onset on survival, the first model was run after excluding age from the model. While the age at disease onset did not appear to be a statistically significant parameter $(p=0.574)$, duration of disease was still highly significant $(\mathrm{p}=0.011)$. Table 4 describes the time related mortality rates for each of these statistically significant parameters after stratification according to clinically important classical thresholds. Among these parameters, poorest prognosis was encountered in patients with albumin level $<2.5 \mathrm{~g} \cdot \mathrm{dL}^{-1}$ at the time of admission.

\section{DISCUSSION}

The present study contributes some new data related to the survival of COPD patients hospitalised for an acute exacerbation. It also lends remarkable support to findings from studies assessing in-hospital and after-discharge survival of COPD patients. The current authors found that the in-hospital mortality rate for the patients was $8.3 \%$ and that the overall mortality rate at $3 \mathrm{yrs}$, one of the longest follow-up periods in the literature, was $49 \%$. Longer duration of disease, longer time elapsed since first hospitalisation, lower $\mathrm{Pa}_{1} \mathrm{O}_{2}$, lower albumin level and lower BMI were the main factors related to long-term

\begin{tabular}{|c|c|c|c|c|c|}
\hline \multirow{3}{*}{$\begin{array}{l}\text { TABLE } 4 \\
\text { Variables }\end{array}$} & \multicolumn{5}{|c|}{$\begin{array}{l}\text { ime dependent mortality rates of statistically } \\
\text { ignificant variables stratified according to the } \\
\text { linically important thresholds }\end{array}$} \\
\hline & \multirow[t]{2}{*}{ Subjects $n$} & \multicolumn{4}{|c|}{ Mortality rates \% } \\
\hline & & 6 month & $1 \mathrm{yr}$ & $2 \mathrm{yr}$ & $3 \mathrm{yr}$ \\
\hline \multicolumn{6}{|l|}{$\begin{array}{c}\text { Duration of } \\
\text { disease }\end{array}$} \\
\hline$<10 \mathrm{yrs}$ & 115 & 17 & 30 & 36 & 43 \\
\hline $10-19$ yrs & 52 & 29 & 34 & 38 & 50 \\
\hline$\geqslant 20 \mathrm{yrs}$ & 38 & 33 & 41 & 51 & 68 \\
\hline \multicolumn{6}{|l|}{$\begin{array}{l}\text { Time since first } \\
\text { hospitalisation }\end{array}$} \\
\hline $\begin{array}{l}\text { Hospitalised for } \\
\text { the first time }\end{array}$ & 49 & 10 & 18 & 20 & 27 \\
\hline $1-5 \mathrm{yrs}$ & 71 & 21 & 29 & 35 & 47 \\
\hline$>5 \mathrm{yrs}$ & 85 & 34 & 45 & 53 & 64 \\
\hline \multicolumn{6}{|l|}{$\mathrm{Pa}, \mathrm{O}_{2}$} \\
\hline$<45 \mathrm{mmHg}$ & 96 & 29 & 42 & 54 & 66 \\
\hline $45-59.9 \mathrm{mmHg}$ & 77 & 26 & 34 & 31 & 40 \\
\hline$\geqslant 60 \mathrm{mmHg}$ & 32 & 0 & 6 & 13 & 19 \\
\hline \multicolumn{6}{|l|}{ BMI } \\
\hline$<20 \mathrm{~kg} \cdot \mathrm{m}^{-2}$ & 58 & 33 & 41 & 47 & 63 \\
\hline $20-24.9 \mathrm{~kg} \cdot \mathrm{m}^{-2}$ & 94 & 21 & 30 & 37 & 46 \\
\hline$\geqslant 25 \mathrm{~kg} \cdot \mathrm{m}^{-2}$ & 53 & 19 & 31 & 34 & 40 \\
\hline \multicolumn{6}{|l|}{ Albumin } \\
\hline$<2.5 \mathrm{~g} \cdot \mathrm{dL}^{-1}$ & 30 & 38 & 63 & 69 & 78 \\
\hline $2.5-3.5 \mathrm{~g} \cdot \mathrm{dL}^{-1}$ & 96 & 27 & 38 & 45 & 63 \\
\hline$>3.5 \mathrm{~g} \cdot \mathrm{dL}^{-1}$ & 79 & 14 & 16 & 20 & 23 \\
\hline
\end{tabular}

Data are presented as $\mathrm{n}$ or $\% . \mathrm{Pa}_{1} \mathrm{O}_{2}$ : arterial oxygen tension; $\mathrm{BMI}$ : body mass index. $\mathrm{kPa}=\mathrm{mmHg} \times 0.133$.

mortality after index hospitalisation with acute exacerbation of COPD

The rate of in-hospital mortality for COPD patients hospitalised with acute exacerbation has been reported to be between $2.5 \%$ and $30 \%$, depending on the methodology of data collection and the patient population $[5,16]$. Nonrespiratory organ system dysfunction and hospital days prior to ICU admission have been reported to be the most important predictors of in-hospital mortality, with the total in-hospital mortality rate being $24 \%$ [5]. Others have reported an inhospital mortality rate of $14.4 \%$, with cardiac dysfunction being an important predictor of mortality [6]. Recently, a crosssectional nationwide study based on a national database reported a relatively low in-hospital mortality of $2.5 \%$ and identified older age, male sex, higher income, nonroutine admissions, and more comorbid conditions as independent risk factors [16]. The present study found, however, that inhospital mortality of COPD patients hospitalised for acute exacerbation was mainly influenced by lower $\mathrm{Pa}, \mathrm{O}_{2}$ and $\mathrm{Sa}_{1} \mathrm{O}_{2}$, higher $\mathrm{Pa}_{\mathrm{a}} \mathrm{CO}_{2}$, and longer length of hospital stay. Of these parameters, only $\mathrm{Pa}_{1} \mathrm{CO}_{2}$, at a cut-off of $6.916 \mathrm{kPa}$, demonstrated a relatively high sensitivity $(0.71)$ and specificity (0.69). Admission to the ICU, which is virtually the end result of multiple clinical parameters, was associated with $>70 \%$ of 
the in-hospital deaths in this study. When the ICU and nonICU patients were categorised, the factors associated with ICU admission were found to be almost identical to the factors related to in-hospital mortality. Indeed, studies designed to identify the factors that direct a clinician to decide whether to admit a patient to the ICU may be another important step in determining the factors related to short-term survival.

A study on long-term survival of seriously ill, hospitalised COPD patients with $\mathrm{Pa}_{1} \mathrm{CO}_{2} \geqslant 6.65 \mathrm{kPa}$ showed that independent predictors for survival were severity of illness, age, prior functional status, $\mathrm{BMI}, \mathrm{Pa}_{\mathrm{a}} \mathrm{O}_{2} /$ inspiratory oxygen fraction, congestive heart failure, serum albumin level and presence of cor pulmonale [8]. In-hospital and 2-yr mortality rates after allcause hospitalisations were $11 \%$ and $49 \%$, respectively. The patient selection and flexible margins for cause of hospitalisation, however, make it difficult to generalise these results to all COPD patients. In another study, long-term mortality in patients admitted to the ICU with acute exacerbations was shown to be related to severity of respiratory organ dysfunction and the presence of nonrespiratory organ dysfunction [5]. While they reported a 1-yr mortality rate of $48 \%$, a major limitation of that study was the inability to obtain follow-up data from $54 \%$ of the patients [5]. In contrast, the number of patients missing on follow-up in the current study was very small. A multi-centre study from Spain which analysed the association between re-admission of COPD patients and multiple modifiable factors reported a 1 -yr after-discharge mortality rate of $29 \%$, but there was no analysis of survival or mortality related to hospitalisation period [17].

As described above, only one study in the literature is comparable to the present study in directly addressing the long-term survival of all COPD patients hospitalised with acute exacerbations [9]. This study reported that older age, longer stay in the hospital, comorbidity index, low FEV1, higher $\mathrm{Pa}, \mathrm{CO}_{2}$ and use of maintenance oral corticosteroids were factors related to mortality [9]. The current findings regarding long-term mortality are somewhat different. This difference may be due to the different methodologies employed and the use of a longer follow-up period. As compared, the present model did not include analyses for sex and maintenance oral corticosteroid use. Sex was excluded because only $12 \%$ of the patients were females, due to the low smoking rate among older females in Turkey. Although the limited number of female patients in this study can be considered a problem for the generalisation of the data, varying degrees of male predominance have been accepted, for socio-economic reasons, worldwide.

As the Turgut Ozal Research Centre is the largest medical facility in the region, as well as being the only training and research centre, the current authors either directly treat the great majority of the COPD patients or consult in their diagnosis and treatment. For any patient classified as having COPD, the long-term treatment policy is not to prescribe maintenance oral corticosteroids. These patients are only allowed to use systemic corticosteroids during the treatment of acute exacerbations. Since this became a common practice in the authors region, no patients utilising maintenance systemic corticosteroids were seen during the study period. Thus, this parameter was excluded from consideration.

It was found that the statistically significant parameters related to mortality were lower $\mathrm{Pa}_{2} \mathrm{O}_{2}$, lower albumin level, lower $\mathrm{BMI}$ and longer duration of disease. Low $\mathrm{Pa}_{2} \mathrm{O}_{2}$ is direct evidence for limited pulmonary reserve and increased ventilation/perfusion mismatch, thus, emphasising the severity of the underlying disease. The critical level appeared to be $5.985 \mathrm{kPa}$ in the present study (table 4). These patients became less tolerant to alterations in their clinical condition, thus, showing a poorer prognosis.

Compatible with the current results, low BMI [7] and low serum albumin level [8] have been shown to be strong predictors of poor long-term survival. The suggested mechanisms for their roles in increased long-term mortality are respiratory muscle weakness, impaired gas exchange and impaired immune response. BMI is not generally thought to be influenced by acute events; rather, it correlates better with chronic health status. In agreement with this, it was found that BMI did not appear to be an important parameter for in-hospital mortality. For long-term mortality, the critical level appeared to be $20 \mathrm{~kg} \cdot \mathrm{m}^{-2}$ (table 4), below which mortality increased. In agreement with previous findings [18], the survival of overweight and obese patients was found to be increased, suggesting that increased BMI has a protective effect. When compared with patients having a BMI $<20 \mathrm{~kg} \cdot \mathrm{m}^{-2}$, those who were overweight or obese had a $33 \%$ decreased probability of death throughout the 3-yr period.

Serum albumin level has been considered to be part of the acute phase protein response. Low levels of this protein may, therefore, reflect a deterioration of clinical status or increased persistent inflammation during acute exacerbations of COPD. However, low serum albumin level is also a good indicator for long-term health status in chronically ill patients. Due to the low number of in-hospital deaths in the current study, present analysis could only show a relationship between low serum albumin level and higher long-term mortality. The clinically important threshold for mortality was $2.5 \mathrm{~g} \cdot \mathrm{dL}^{-1}$ albumin, below which the mortality rate during follow-up increased sharply (table 4). Approximately onethird and one-fifth of patients could survive beyond 1 and 3 yrs, respectively. When combined with disability and dependence on others, albumin values $<2.5 \mathrm{~g} \cdot \mathrm{dL}^{-1}$ may help clinicians discuss more conservative treatment options with patients and their relatives.

To the authors' knowledge, the present study is the first to show that longer duration of disease and time elapsed since first hospitalisation are predictors of mortality. These two parameters, however, are somewhat subjective, if directly asked to the patient. The date of first visit to a doctor for chronic cough, dyspnoea and/or sputum production to determine disease duration was used. This information, as well as the date of first hospitalisation, are usually recorded in personal and official medical documents and are relatively easy for patients to remember. Since all patients in the current study were handled individually and without time limitation by a team of investigators who were aware of the risks, the authors believe that the multiple questionings minimised 
these risks and lowered the chance of obtaining misleading information.

Table 4 shows the relationship between disease duration/time elapsed since first hospitalisation and mortality at different cut-off levels. Patients with disease duration $\geqslant 20$ yrs and $>5$ yrs since first hospitalisation had higher mortality rates. Since COPD is a progressive disease and the general status of patients unavoidably deteriorates over time, the impact of these two parameters on survival appears indisputable. The correlation between disease duration and time elapsed since the first hospitalisation was so high that these two parameters can be used interchangeably in future studies. To determine the real influence of these new parameters on the model, it was run without them. When the authors did this, previously significant parameters remained significant, while FEV1/FVC $(\mathrm{p}=0.023), \mathrm{Pa}_{1} \mathrm{CO}_{2}(\mathrm{p}=0.007)$ and Systolic $P \mathrm{pa}(\mathrm{p}=0.028)$ also appeared to be statistically significant. These latter parameters have been frequently linked to mortality. Thus, this analysis suggests that these parameters may be cofactors dependent on disease duration and time elapsed since first hospitalisation. Since the latter two parameters have never been included in previous survival models, this relationship may not have been revealed. In addition, the current analysis of age at disease onset using Cox regression analysis also failed to show any relationship to mortality. Inclusion of age at disease onset with duration of disease also did not significantly alter the statistical values of the other parameters. Thus, the present results suggest that neither age nor age at disease onset independently influences mortality. Rather, duration of disease is the only one of these three parameters that has a strong and independent relationship to mortality. However, these findings must be validated in future studies.

The National Health and Nutrition Examination Survey III study [19] showed that only 10-15\% of all COPD patients are hospitalised, with the majority likely to be those with severe disease. Hence, the expected conclusion should be that the results of studies on hospitalised COPD patients may be specific to this group, and cannot be generalised for nonhospitalised COPD patients. Interestingly, the related data for this major group is extremely limited. Nevertheless, SORIANO et al. [20] recently published a study directly addressing the survival of newly physician-diagnosed COPD patients identified in primary care. This large retrospective cohort study which was based on evaluation of national database revealed that the overall 3-yr mortality rate for these patients was around $33 \%$. This high rate is quite surprising because the patients were nonhospitalised and virtually represented the general COPD outpatients quite well. Confirming the findings of SORIANO et al. [20], almost identical mortality rates for outpatients with COPD were reported very recently by CELLI et al. [21]. They also designed an index for predicting the risk of death in outpatients with COPD. This index, called the BODE index, consists of four parameters: BMI, degree of airflow obstruction, level of dyspnoea and exercise capacity. It was found to be better than FEV1 in predicting the risk of death [21]. In designing the regression model, the authors also included both BMI and FEV1, and found that BMI had a statistically significant influence on patient mortality. As in the current study, BMI has been widely recognised as having an influence on long-term mortality in both hospitalised and outpatients with COPD. In the present authors' opinion, these high morality rates strongly emphasise the poor long-term survival of COPD patients in general.

One limitation is that only overall death rates were reported, not the specific cause of death. Unfortunately, official records in some countries do not enable the investigators to identify the specific cause of death at all. To date, a few studies have been able to provide this specific data for patients with COPD, showing that $>60 \%$ of outpatients and $>80 \%$ of hospitalised patients die from COPD during follow-up $[17,20]$. Thus, the absence of exact cause of death is not considered to be a serious limitation in interpreting the data.

In conclusion, it has been shown that half of all chronic obstructive pulmonary disease patients hospitalised with acute exacerbations died within 3 yrs. These findings may help clinicians with important information about the probable short- and long-term survival of these patients. Thus, low levels of serum albumin strongly predict poorer long-term outcome, and longer duration of disease and longer time elapsed since first hospitalisation appear as new mortalityrelated independent factors. The authors believe that the current findings will provide clinicians with new insights, allowing them to implement more individualised treatment strategies by better predicting the life expectancy of chronic obstructive pulmonary disease patients.

\section{REFERENCES}

1 Murray CJL, Lopez AD. Evidence based health policylessons from the Global Burden of disease Study. Science 1996; 274: 740-743.

2 World Health Report. World Health Organisation, Geneva. 2000. www.who.int/whr/2000/en/statistics.htm. Date accessed: January 2004.

3 Mannino DM. COPD: epidemiology, prevalence, morbidity, and mortality, and disease heterogeneity. Chest 2002; 121: Suppl. 5, 121S-126S.

4 Anthonisen NR, Wright EC, Hodgkin JE. Prognosis in chronic obstructive pulmonary disease. Am Rev Respir Dis 1986; 133: 14-20.

5 Seneff MG, Wagner DP, Wagner RP, et al. Hospital and 1year survival of patients admitted to intensive care units with acute exacerbation of chronic obstructive pulmonary disease. JAMA 1995; 274: 1852-1857.

6 Fuso L, Incalzi RA, Pistelli R, et al. Predicting mortality of patients hospitalised for acutely exacerbated chronic obstructive pulmonary disease. Am J Med 1995; 98: 272-276.

7 Landbo C, Prescott E, Lange P, et al. Prognostic value of nutritional status in chronic obstructive pulmonary disease. Am J Respir Crit Care Med 1999; 160: 1856-1861.

8 Connors AF, Dawson NV, Thomas C, et al. Outcomes following acute exacerbation of severe chronic obstructive pulmonary disease. Am J Respir Crit Care Med 1996; 154: 959-967.

9 Groenewegen KH, Schols AMWJ, Wouters EFM. Mortality and mortality-related factors after hospitalisation for acute exacerbation of COPD. Chest 2003; 124: 459-467.

10 American Thoracic Society. Standards for the diagnosis and care of patients with chronic obstructive pulmonary 
disease (COPD) and asthma. Am Rev Respir Dis 1987; 136: 225-244.

11 Charlson ME, Pompei P, Ales KL, et al. A new method of classifying prognostic comorbidity in longitudinal studies: development and validation. J Chronic Dis 1987; 40: 373-383.

12 Celli BR, MacNee W. Standards for the diagnosis and treatment of patients with COPD: a summary of the ATS/ ERS position paper. Eur Respir J 2004; 23: 932-946.

13 ATS Statement. Standardization of spirometry-1994 update. Am J Respir Crit Care Med 1995; 152: 1107-1136.

14 Battle R, Davitt MA, Cooper SM, et al. Prevalence of pulmonary hypertension in limited and diffuse scleroderma. Chest 1996; 110: 1515-1519.

15 Higham MA, Dawson M, Joshi J, et al. Utility of echocardiography in assessment of pulmonary hypertension secondary to COPD. Eur Respir J 2001; 17: 350-355.

16 Patil SP, Krishnan JA, Lechtzin N, et al. In-hospital mortality following acute exacerbations of COPD. Arch Intern Med 2003; 163: 1180-1186.
17 Garcia-Aymerich J, Farrero E, Felez MA, et al. Risk factors for readmision to hospital for a COPD exacerbation: a prospective study. Thorax 2003; 58: 100-105.

18 Schols AMW, Slangen J, Volovics L, Wouters EFM. Weight loss is a reversible factor in the prognosis of chronic obstructive pulmonary disease. Am J Respir Crit Care Med 1998; 157: 1791-1797.

19 Mannino DM, Homa DM, Akinbami LJ, et al. Chronic obstructive pulmonary disease surveillance-United States, 1971-2000. Respir Care 2002; 47: 1184-1199.

20 Soriano JB, Vestbo J, Pride NB, et al. Survival in COPD patients after regular use of fluticasone propionate and salmeterol in general practice. Eur Respir J 2002; 20: 819-825.

21 Celli BR, Cote CG, Marin JM, et al. The body-mass index, airflow obstruction, dyspnea, and exercise capacity index in chronic obstructive pulmonary disease. N Engl J Med 2004; 350: 1005-1012. 